\title{
Clock genes and salt-sensitive hypertension: a new type of aldosterone-synthesizing enzyme controlled by the circadian clock and angiotensin II
}

\begin{abstract}
Hitoshi Okamura ${ }^{1,2}$, Masao Doi ${ }^{1,2}$, Kaoru Goto ${ }^{1}$ and Rika Kojima ${ }^{1,2}$
With the current societal norm of shiftwork and long working hours, maintaining a stable daily life is becoming very difficult. An irregular lifestyle disrupts circadian rhythms, resulting in the malfunction of body physiology and ultimately leading to lifestylerelated diseases, including hypertension. By analyzing completely arrhythmic Cry1/Cry2 double-knockout (Cry-null) mice, we found salt-sensitive hypertension accompanied by hyperaldosteronism. On the basis of a DNA microarray analysis of the adrenal

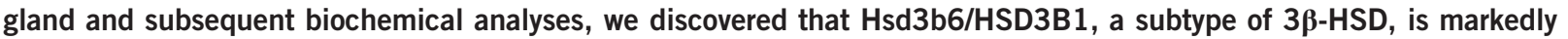
overexpressed in aldosterone-producing cells in the Cry-null adrenal cortex. In addition, we found that Hsd3b6/HSD3B1, which converts pregnenolone to progesterone, is a clock-controlled gene and might also be a key enzyme for the regulation of aldosterone biosynthesis, in addition to the previously established CYP11B2, which synthesizes aldosterone from deoxycorticosterone. Importantly, angiotensin II induces HSD3B1 via the transcription factor NGFIB in human adrenocortical H295R cells, similarly to CYP11B2. As HSD3B1 levels are abnormally high in the adrenal aldosterone-producing cells of idiopathic hyperaldosteronism (IHA), the temporal component of this system in the pathophysiology of IHA is a promising area for future research.
\end{abstract}

Hypertension Research (2016) 39, 681-687; doi:10.1038/hr.2016.91; published online 21 July 2016

Keywords: angiotensin II; clock gene; HSD3B1; primary aldosteronism; steroidogenesis

\section{INTRODUCTION}

It has long been known that biological rhythms are an important factor influencing blood pressure. Specifically, blood pressure begins to rise at dawn, continues to increase throughout the morning, reaches a peak at noon, decreases in the afternoon and reaches a minimum late at night. This blood pressure rhythm is also observed in patients with high blood pressure; however, those with pathological conditions, such as rhythm-deficient 'non-dippers' and 'risers' who demonstrate contrasting diurnal variation, are at risk of cardiovascular complications and thus require intensive care. ${ }^{1}$ In addition, blood pressure tends to increase with rotating shiftwork, long working hours and other dysregulating biological rhythms. ${ }^{2}$ However, the mechanisms by which biological rhythms regulate blood pressure and the reason why rhythm abnormalities lead to high blood pressure are unknown.

In studies to determine the physiological role of the circadian clock in mammals, we discovered that arrhythmic $\mathrm{Cr} y 1^{-/-} \mathrm{Cr} y 2^{-/-}$mice, due to the loss of the circadian oscillatory machinery, had abnormal increases in adrenal aldosterone production and demonstrated saltsensitive hypertension. ${ }^{3}$ In this analysis, $3 \beta$-hydroxysteroid dehydrogenase-isomerase ( $3 \beta-\mathrm{HSD})$, the enzyme responsible for the synthesis of progesterone from pregnenolone, emerged as a new ratelimiting step in aldosterone synthesis. Recent translational research in humans has suggested that this enzyme is involved in the pathogenesis and development of primary aldosteronism. ${ }^{4,5}$ Aldosterone regulates sodium and water homeostasis, and its excess production increases the risk of cardiovascular damage via the stimulation of mineralocorticoid receptors. ${ }^{6,7}$ In this review, we outline a potential path by which the biological rhythm system - a physiological phenomenon defined by genes - controls blood pressure by regulating enzymes engaged in aldosterone biosynthesis.

\section{CLOCK GENES AND CLOCK-CONTROLLED GENES ASSOCIATED WITH BIOLOGICAL RHYTHM}

With the discovery of clock genes in 1997 in mice and humans, the concept of biological rhythms was changed from its very foundation. ${ }^{8}$ According to the new viewpoint, biological rhythms are produced by the evolutionarily conserved transcription and translation feedback loops of clock genes within the body's tens of trillions of cells. ${ }^{9,10}$ Within the cells, the periodic expression of these clock genes establishes a 24-h dynamic state of equilibrium for basic cell functions,

\footnotetext{
${ }^{1}$ Department of Systems Biology, Graduate School of Pharmaceutical Sciences, Kyoto University, Kyoto, Japan and ${ }^{2}$ Core Research for Evolutional Science and Technology, Japan Science and Technology Agency, Kawaguchi, Japan

Correspondence: Professor H Okamura, Department of Systems Biology, Graduate School of Pharmaceutical Sciences, Kyoto University, Kyoto 606-8501, Japan.

E-mail: okamurah@pharm.kyoto-u.ac.jp

Received 20 May 2016; revised 6 June 2016; accepted 6 June 2016; published online 21 July 2016
} 


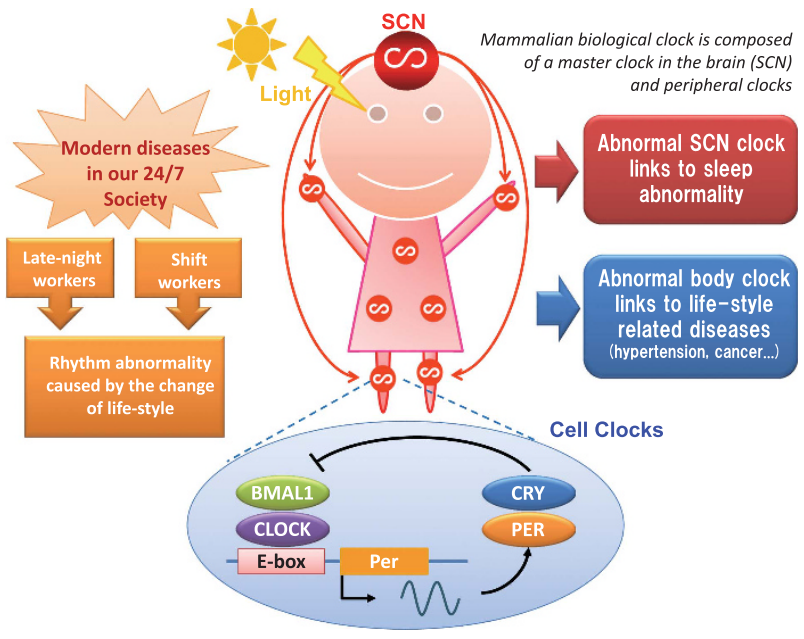

Figure 1 The biological clock system and its abnormalities. The human biological clock system comprises tens of trillions of cellular clocks and the central clock in the SCN that manages them. Through rapid changes in lifestyle, we now live in a 24/7 society, which perturbs the proper oscillation of the biological clock. An SCN clock that is disrupted by irregular environmental lights will lead to sleep disorders, and abnormal cellular clocks of entire body organs raise concerns about lifestyle-related diseases. The feedback loop of intracellular clock genes is illustrated (lower). The core is composed of clock genes, such as Per1/Per2, Cry1/Cry2, Clock and Bmal1.

such as cell metabolism and the cell cycle. ${ }^{11}$ These individual cellular clocks throughout the body are integrated via the central clock in the suprachiasmatic nucleus of the brain. ${ }^{12}$ Suprachiasmatic nucleus-evoked time signals are transmitted to the clocks of peripheral cells through the sympathetic nervous system, parasympathetic nervous system and the glucocorticoids from the adrenal gland (Figure 1, upper). ${ }^{13}$

At the molecular level, the transcription and translation feedback loops that create cellular clocks are composed of positive regulators, that is, Clock and Bmal1, and negative regulators, that is, Per (Per1, Per2 and Per3) and Cry (Cry 1 and Cry2) (Figure 1, lower). Cellular clocks transmit time signals to regulate intracellular metabolism by controlling thousands of clock-controlled genes $(c c g s) ;{ }^{14}$ this concept was first reported for the circadian system of Neurospora. ${ }^{15}$ Clock genes, as transcription regulators, directly control $c c g s$ at the transcriptional level to some extent via cis-elements, such as E-box, D-box and Ror. ${ }^{11,14}$ These $c c g s$ are not just involved in universal cell functions, such as nucleic acid metabolism, ${ }^{16}$ glucose homeostasis ${ }^{17}$ and the cell cycle, ${ }^{18}$ but also in cell-specific functions. ${ }^{19}$ Thus, the identification of ccgs is critically important to address the role of the circadian clock in the physiology and pathology of disease.

\section{RHYTHM-DEFICIENT, CRY-NULL MICE DEMONSTRATE SALT-SENSITIVE HYPERTENSION}

The dysregulated rhythm of circadian clocks in various organs might disrupt the proper performance of the specified functions of peripheral organs and ultimately lead to disease. To verify this hypothesis, attempts have been made to establish genetically engineered mice with the absence of rhythm. Van der Horst et al. ${ }^{20}$ demonstrated that circadian locomotor rhythms are completely blocked in mice with deletions of both Cry1 and Cry2. In collaboration with his group, we established that Cry1/Cry2 double-knockout mice (hereafter referred to as Cry-null) exhibit complete loss of rhythms in both central and peripheral clocks. ${ }^{21,22}$ The Cry-null mice are the first established mouse model that completely lacks clock oscillation throughout the whole body. As blood pressure is a marked physiological output of the circadian clock and the loss of rhythm is known to increase the frequency of cardiovascular complaints, we investigated the circadian blood pressure of these mice. ${ }^{3}$ For a normal diet containing $0.2 \% \mathrm{Na}^{+}$, blood pressure in Cry-null mice was within the healthy range, but the diurnal rhythm of the mean arterial pressure was lost. However, when given a high salt diet, the blood pressure of Cry-null mice increased day by day, and after 1 week it increased by $\sim 30 \mathrm{~mm} \mathrm{Hg}$ (Figure 2, upper left). Under these salt-loaded conditions, normal wild-type mice never exhibited an increase in blood pressure. In other words, the Cry-null mice developed salt-sensitive, non-dipper-type hypertension. ${ }^{1}$

What mechanisms are involved in the hypertension of saltloaded Cry-null mice? Cardiac output and peripheral resistance are the two determinants of arterial blood pressure. The following three theories have been proposed to explain this: (1) an overactive renin-angiotensin system leads to vasoconstriction and the retention of sodium and water, (2) the increase in blood volume leads to hypertension and (3) an overactive sympathetic nervous system leads to increased stress responses. We began examining the state of humoral factors in Cry-null mice, and we found that the plasma aldosterone concentration is markedly increased in Cry-null mice (5-10 times higher than in wild-type (WT) mice). ${ }^{3}$ As plasma renin levels were reduced in Cry-null mice, the increase of plasma aldosterone is not caused by the activation of the renin-angiotensin system. To check whether aldosterone production is increased in the adrenals, we eviscerated the adrenals, examined aldosterone release from this ex vivo explant, and found a remarkable increase of aldosterone release into the medium. These findings strongly suggest that increased plasma aldosterone in Cry-null mice is caused by the increased synthesis of aldosterone within the adrenal glands (Figure 2, upper middle).

We applied a DNA microarray to the adrenal gland to identify the causative molecules out of the dozens of enzymes involved in steroid synthesis, and we found that a new mouse subtype of $3 \beta$-HSD called Hsd3b6 was expressed at very high levels in Cry-null mice. ${ }^{3}$ Hsd3b6 localized in cells in the zona glomerulosa, but not in the zona fasciculata of the adrenal gland $d^{3,23}$ and it is rhythmically expressed in a circadian manner in WT mice. We also found that this enzyme is a clock-controlled gene $(c c g)$ regulated by a D-box cis element on its promoter (Figure 2).

\section{STRONG CONTROL WITH HSD3B1, ANGIOTENSIN II AND AT1 RECEPTORS}

Is Hsd3b6 controlled only by the clock, or is it controlled by other factors as well? Indeed, when mice are housed with a low salt diet, it was found that Hsd3b6 is induced in the zona glomerulosa. ${ }^{23}$ As it is well known that the renin-angiotensin system is activated under low salt conditions, we speculated that angiotensin II is an inducer of the low-salt activation of Hsd3b6; after a single dose of angiotensin II, Hsd3b6 was strongly induced in the zona glomerulosa. ${ }^{24}$ To understand whether a similar system occurred in human adrenals, we examined its cellular mechanisms in H295R, a cell line derived from a human adrenal gland tumor. We found that angiotensin II induces HSD3B1, the human homolog of the mouse Hsd3b6, through the activation of AT1 receptors (Figure 3a). As this induction was completely blocked by the simultaneous application of protein synthesis inhibitor cycloheximide, ${ }^{24}$ HSD3B1 induction is performed 


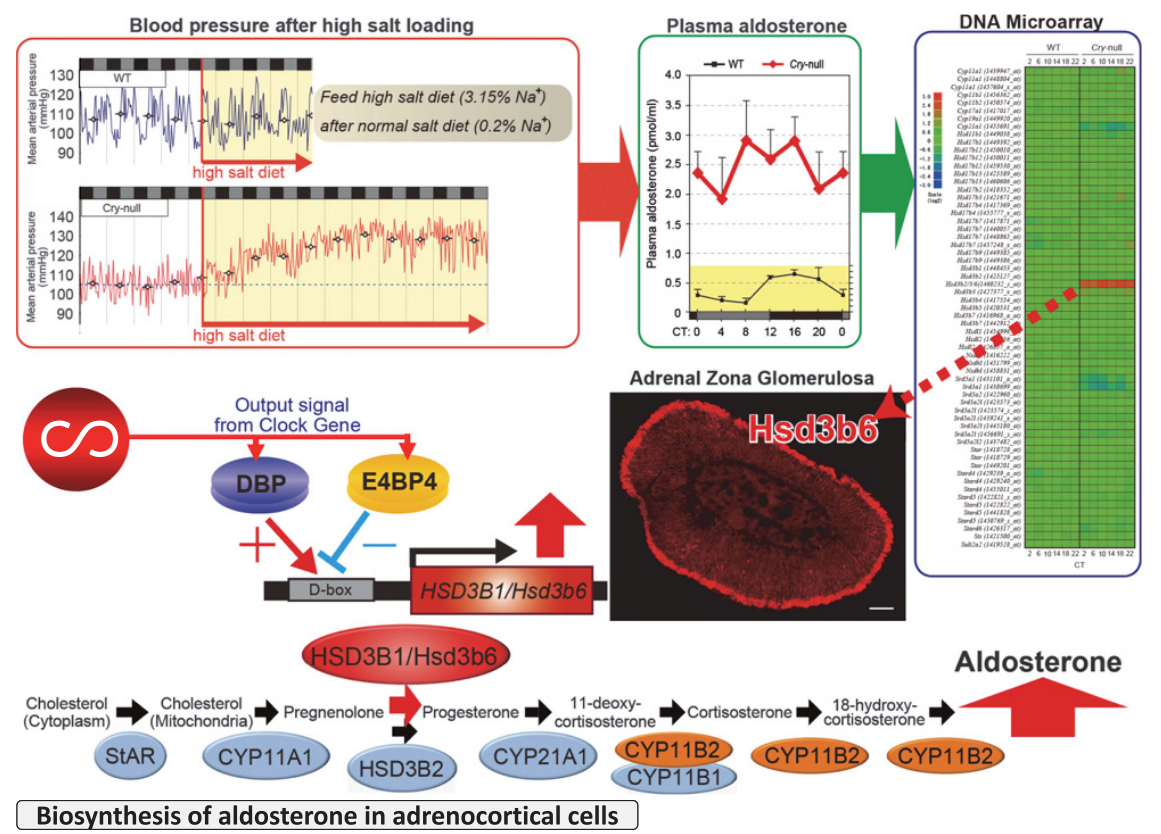

Figure 2 Salt-sensitive hypertension and adrenal aldosterone-producing cellular clocks. The upper left of the figure shows the average ambulatory aortic blood pressure by using a telemetry system. The day and night difference in blood pressure is observed in WT mice, whereas this day and night rhythm is abolished in Cry-null mice. Even when the normal diet (0.2\% sodium) was changed to a high salt diet $(3.15 \%$ sodium), the blood pressure did not change in WT mice; however, in Cry-null mice, blood pressure gradually rose and reached a plateau after $\sim 1$ week. The upper middle of the figure shows the 24-h rhythm of the plasma aldosterone concentration. In WT mice, there is a weak rhythm with a peak at night; however, in Cry-null mice, plasma aldosterone concentrations are constantly extremely high and the rhythm has disappeared. CT indicates the circadian time that shows the phases of the endogenous rhythm. CTO and CT12 correspond to the start of the subjective light (dawn) and dark periods (dusk), respectively. The upper right of the figure shows the DNA microarray analysis using the adrenal glands of the Cry-null and WT mice. The expression of the genes involved in steroid synthesis was analyzed at six time points throughout the day. In the adrenal glands of the Cry-null mice, a probe that recognizes Hsd3b6 showed abnormally high values throughout the day. In the bottom of the figure, a scheme demonstrates the role of the clock in the aldosterone cells of the zona glomerulosa of the adrenal gland. The positive cellular clock regulator, DBP and negative regulator, E4BP4, act competitively with the D-box of the HSD3B1/Hsd3b6 promoter, leading to rhythms in the expression. Namely, it shows that Hsd3b6 is a clock-controlled gene. In the Cry-null mice, compared with the constant maximum values demonstrated by DBP, E4BP4 remains at comparatively low values, making the transcription balance positive, and Hsd3b6 mRNA increases. The middle left of the figure shows the specific expression in the zona glomerulosa (red) through immunohistochemical staining, using the antibody for the Hsd3b6 protein. The lowest portion shows the adrenal steroid synthesis enzyme for the transition from cholesterol to aldosterone and its metabolites. HSD3B1 and CYP11B2 are enzymes specific to the zona glomerulosa of the adrenal gland. HSD3B1/Hsd3b6 and CYP11B2 are enzymes that exist only in the aldosterone cells and only within the adrenal gland. Excluding the lowest portion of the figure, all information is adapted from Doi et al. ${ }^{3}$ with permission.

not by a pre-existing protein, but rather by a newly synthesized protein that is likely to be occurring via a transcription factor. What could this transcription factor be? As the NBRE (NGFIB-binding motif) sequence localizes in the vicinity of the transcription initiation site of the HSD3B1 promoter, we speculate that the orphan nuclear receptor family NGFIB (NGFIB, NURR1 and NOR), which binds to NBRE, is involved in this induction.

Interestingly, the administration of angiotensin II immediately induced NGFIB and NURR1 in H295R cells. ${ }^{24}$ In gel shift and chromatin immunoprecipitation assays, NGFIB bound to the HSD3B1 promoter (Figure $3 \mathrm{~b}$ ). Next, to determine whether angiotensin II was actually acting on NGFIB to induce HSD3B1, dominant negative (DN) mutants, which have altered gene products of NGFIB with no transcriptional activity and have a dominant phenotypic effect over any WT NGFIB, were induced in the cells and investigated (Figure 3c). It was found that although HSD3B1 activity was comparatively higher in cells not carrying the DN mutation, a HSD3B1 increase was not observed in cells harboring the DN mutation even after angiotensin II treatment. Through the above results, it was verified that angiotensin II induces HSD3B1 through the NGFIB family of orphan nuclear receptors.
What about the role of $\mathrm{K}^{+}$in the secretion of aldosterone? In $\mathrm{H} 295 \mathrm{R}$ cells, $\mathrm{K}^{+}$stimulation activates neither NGFIB nor HSD3B1, ${ }^{25}$ although it stimulates CYP11B2, the enzyme for the final step in the synthesis of aldosterone, via the activation of CREB/ATF family members. We are therefore extremely interested in the idea that external stimuli are able to regulate differently the two distinct enzymatic steps required for aldosterone synthesis.

\section{TRANSLATIONAL RESEARCH TO PRIMARY ALDOSTERONISM}

$3 \beta$-HSD in humans has two subtypes, HSD3B1 and HSD3B2. Until now, only HSD3B2 was known to exist in the adrenal gland. Using a laser microdissection that allows for extraction at the cellular level and the TaqMan MGB probe that recognizes single-nucleotide sequence differences, we revealed the enzyme HSD3B1, corresponding to the mouse Hsd3b6, exists only in the aldosterone-producing cells in humans as well.

Furthermore, to explore the role of this enzyme in the pathogenesis of human hypertension, we generated HSD3B1- and HSD3B2-specific monoclonal antibodies ${ }^{4}$ and examined their expression profiles in the adrenal cortexes of patients who suffered from primary aldosteronism by using immunohistochemistry. ${ }^{4,5}$ 
a

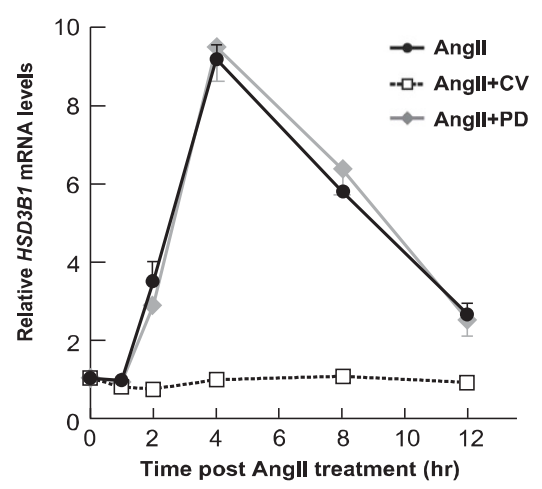

b

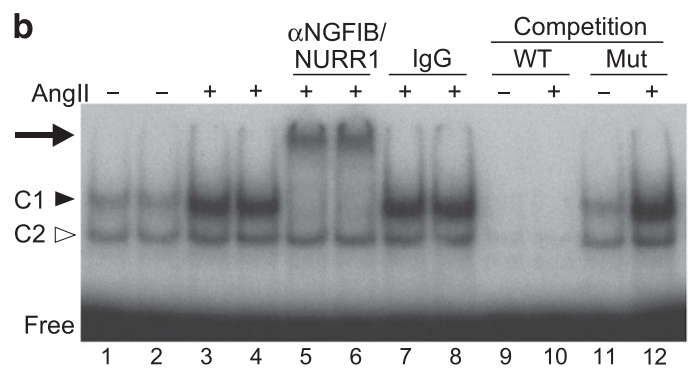

c

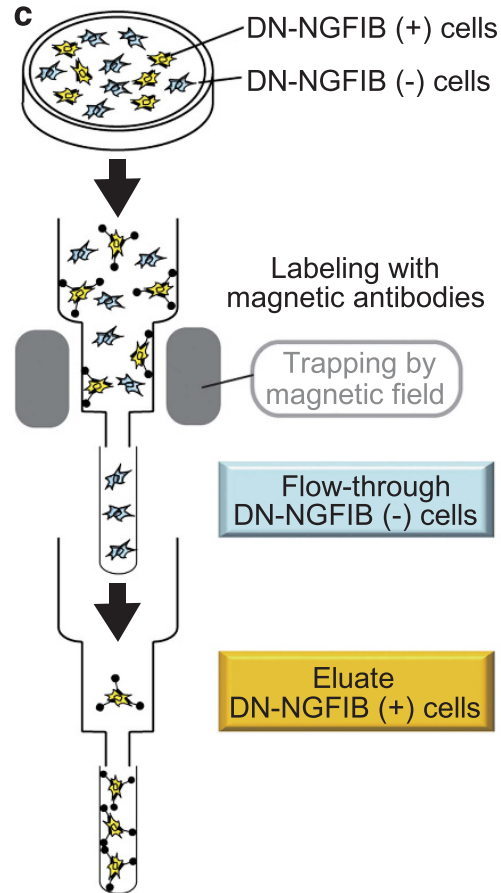

DN-NGFIB (-) cells

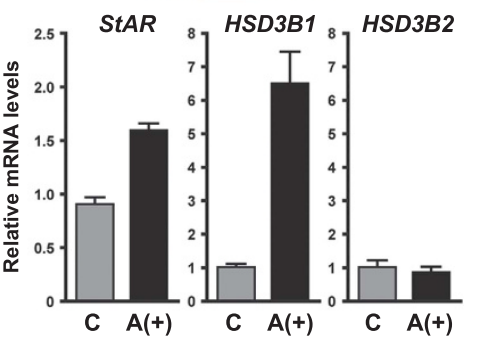

DN-NGFIB (+) cells

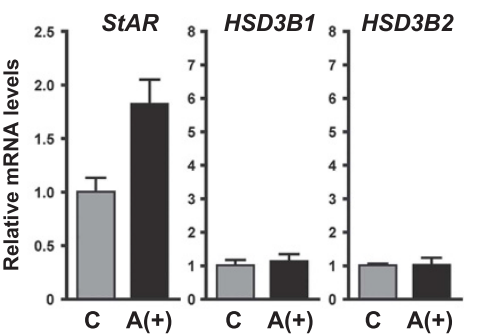

Figure 3 Angiotensin II induces expression of HSD3B1 through NGFIB in H295R cells. (a) Angiotensin II (AngII)-induced expression in the human adrenal cortex-derived H295R cells. HSD3B1 peaked at $4 \mathrm{~h}$ after Angll treatment (100 nm). This induction was completely suppressed with the AT1 receptor antagonist CV11974 (100 nм) but was not suppressed with the AT2 receptor antagonist PSD123319 (PD; $1 \mu \mathrm{m}$ ). (b) NGFIB binds to the NBRE sequence of the HSD3B1 promoter in H295R cells. In a gel shift assay, increased NGFIB binding was observed after Angll treatment (C1, lanes 3 and 4). The arrow indicates a supershift band caused by anti-NGFIB/NURR1 antibody (lanes 6 and 7). Normal IgG was used as a control. Cold probe completion with WT (lanes 9 and 10), but not mutant (lanes 11 and 12), NBRE led to the loss of the observed NGFIB binding. (c) Transfection with a dominant negative NGFIB (DN-NGFIB) interferes with Angll-triggered HSD3B1 expression in H295R cells. Because of the low efficiency of transfection, transfected H295R cells were separated from those not transfected with a magnetic separation system. Briefly, a cell-surface selection marker was co-transfected with DN-NGFIB. This, in combination with the use of a magnetically labeled, anti-cell-surface marker antibody, allows for the trapping of DN-NGFIB-positive (+) transfected cells with a magnetic field. Quantitative RT-PCR analysis reveals that Angll treatment $(A(+))$-induced induction of HSD3B1 was completely blocked in DN-NGFIB (+) cells, while it remained normal for control DN-NGFIB (-) cells. Expression levels of StAR and HSD3B2 were unimpaired by DN-NGFIB. Adapted with permission Ota et al.24

Primary aldosteronism is characterized by excess production of the hormone aldosterone by the adrenal glands, resulting in low plasma renin levels. Increased aldosterone increases the absorption of sodium with water in the kidney tubules, increasing the blood volume and blood pressure. Primary aldosteronism is classified into two subgroups: one is aldosterone-producing adenoma (APA), and the other is idiopathic hyperaldosteronism (IHA) displaying hyperplasia.

In a normal adrenal gland, HSD3B1 is expressed only in the cells of the zona glomerulosa, although HSD3B2 was expressed in both the zona glomerulosa and the zona fasciculata (Figure 4). This distribution pattern supports the idea that HSD3B1 is involved only in aldosterone production and HSD3B2 is involved in both aldosterone and cortisol production. In cases of IHA, HSD3B1 had a markedly increased expression within cells in the zona glomerulosa. In APA tumor cells, HSD3B2 was strongly expressed in almost all the cells, whereas HSD3B1 was rarely observed. Interestingly, for the adrenal glands accompanied by APA, both HSD3B1 and HSD3B2 exhibit drastically suppressed expression within the zona glomerulosa cells. This result indicates that the level of HSD3B enzyme is dynamically regulated by product inhibition due to the massive amount of aldosterone produced by the APA tumor. As such, we propose a model in which aldosterone is produced differently in IHA and APA; in IHA, excess aldosterone is produced by the excess of HSD3B1 in both sides of the adrenal glands with hyperplasia, whereas in APA, excess aldosterone occurs through high HSD3B2 production in tumor cells. Abnormal aldosterone synthesis in primary aldosteronism has long been thought to involve the aldosterone synthase CYP11B2, the laststep enzyme of aldosterone synthesis. However, CYP11B2 is not always highly expressed in the lesions of primary aldosteronism. ${ }^{26,27}$ We therefore speculate that $3 \beta$-HSD provides another rate-limiting step for aldosterone synthesis regulation and hence pertains to the pathogenesis of hyperaldosteronisms in primary aldosteronism.

Finally, Cry-null mice can be used as a new animal model for IHA. As there are no tumors, but there is a trend for hyperplasia in histology and the ability for accelerated aldosterone production in both sides of the adrenal gland, the Cry-null mice could be a model of IHA $^{28}$ and its complications. ${ }^{29}$

\section{CONCLUSION}

Primary aldosteronism, accounting for $10 \%$ of hypertension cases, has received a great deal of recent attention as a treatable form of hypertension. It is associated with a higher rate of circulatory complications, such as atrial fibrillation, than is essential hypertension. ${ }^{7}$ In recent years, somatic gene mutations in the potassium channel KCNJ5, ATP1A1 and CACNA1D have been 


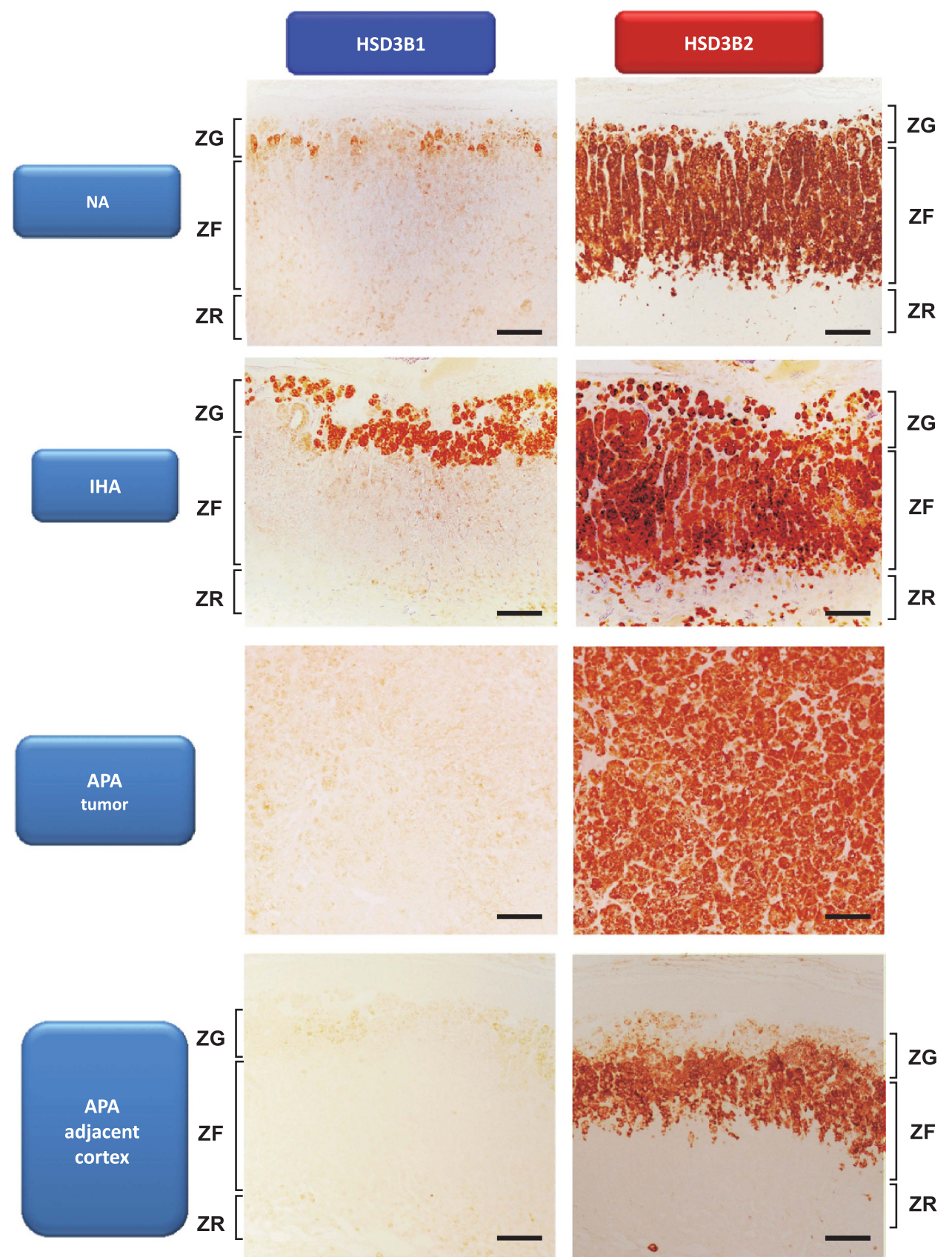

Figure 4 Immunohistochemical analysis of HSD3B1 and HSD3B2 in primary aldosteronism. This figure demonstrates the expression of HSD3B1 and HSD3B2 in a normal adrenal gland (NA), an IHA adrenal gland, an APA tumor and the adrenal cortex adjacent to an APA by using subtype-specific monoclonal antibodies. Note that for each disease type, there are distinct distribution differences. Adapted with permission from Doi et al. ${ }^{3} \mathrm{ZF}$, zona fasciculate; ZG, zona glomerulosa; ZR, zona reticularis.

reported as causes of APA; ${ }^{30-32}$ the increased activity of cells caused by this mutation is thought to be connected to an increase in aldosterone production. Aldosterone biosynthesis involves multiple enzymes; among them, StAR is the aldosterone synthesis enzyme and CYP11B2/aldosterone synthase mediates the last step. On the basis of an analysis of clock-disrupted Cry-null mice showing hyperaldosteronism, we proposed that HSD3B1/Hsd3b6, a new subtype of $3 \beta \mathrm{HSD}$, is a new candidate regulator of aldosterone synthesis. ${ }^{3,4}$ Similar to CYP11B2, this enzyme is also regulated by angiotensin II (Figure 5).
Rotating shiftwork and long working hours are common in the 21st century, reflecting the globalization of economic activity, correlated with an increase in the risk of lifestyle-related diseases. ${ }^{33,34}$ Recent molecular studies of clock-deficient animals have clarified the links between clock dysfunction and several of these diseases ${ }^{35-37}$ Originally, the circadian clock may have functioned as a homeostatic guardian of a variety of cellular metabolic processes in response to daily environmental changes. The temporal components of an aldosteroneregulating system in the pathophysiology of hypertension are promising targets for future research. ${ }^{28}$ 


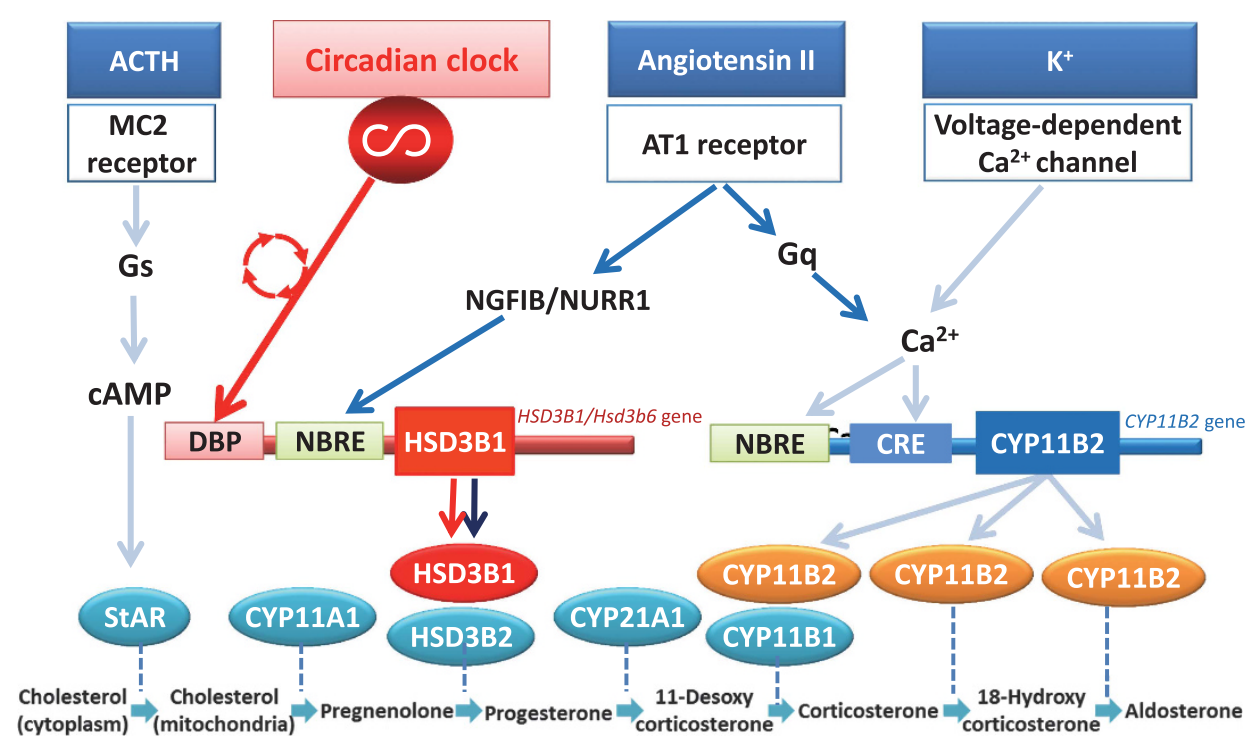

Figure 5 Control of aldosterone synthesis. Regulators of aldosterone synthesis and their possible intracellular mechanisms in aldosterone-producing adrenocortical cells. Among the many steps of aldosterone biosynthesis, three enzymes are claimed to regulate aldosterone production. StAR is known to play a role in an acute control, whereas CYP11B2 contributes to the long-term regulation of aldosterone synthesis; in addition, a new regulator HSD3B1 was revealed as an enzyme that is regulated by Angll. This pathway involves the orphan nuclear receptor NGFIB. Note that ACTH, Angll and potassium ( $\mathrm{K}^{+}$) regulate the expression of these regulators through different intracellular signaling molecules. The circadian clock is also among the regulators of aldosterone synthesis via the regulation of HSD3B1.

\section{CONFLICT OF INTEREST}

The authors declare no conflict of interest.

\section{ACKNOWLEDGEMENTS}

The analysis of 3 $\beta$-HSD expression in primary aldosteronism in humans was conducted in collaboration with Hironobu Sasano and Fumitoshi Satoh of Tohoku University Graduate School of Medicine. This research was supported by Core Research for Evolutional Science and Technology (CREST), SRF, the Funding Program for Next Generation World-Leading Researchers from MEXT and a Genomic Diagnosis of Primary Aldosteronism Research on Measures for Interactive Diseases Grant from MHLW.

1 Yano Y, Kario K. Nocturnal blood pressure and cardiovascular disease: a review of recent advances. Hypertens Res 2012; 35: 695-701.

2 Scheer FA, Hilton MF, Mantzoros CS, Shea SA. Adverse metabolic and cardiovascular consequences of circadian misalignment. Proc Natl Acad Sci USA 2009; 106 : 4453-4458.

3 Doi M, Takahashi Y, Komatsu R, Yamazaki F, Yamada H, Haraguchi S, Emoto N, Okuno Y, Tsujimoto G, Kanematsu A, Ogawa O, Todo T, Tsutsui K, van der Horst GTJ, Okamura H. Salt-sensitive hypertension in circadian clock-deficient mice involves dysregulated adrenal Hsd3b6. Nature Med 2010; 16: 67-74.

4 Doi M, Satoh F, Maekawa T, Nakamura Y, Fustin JM, Tainaka M, Hotta Y, Takahashi Y, Morimoto R, Takase K, Ito S, Sasano H, Okamura H. Isoform-specific monoclonal antibodies against $3 \beta$-hydroxysteroid dehydrogenase/isomerase family provide markers for subclassification of human primary aldosteronism. J Clin Endocrinol Metab 2014; 99: E257-E262.

5 Konosu-Fukaya S, Nakamura Y, Satoh F, Ono Y, Felizola SJ, Ise K, Maekawa T, Takeda K, Katsu K, Fujishima F, Kasajima A, Watanabe M, Arai Y, Gomez-Sanchez EP, Gomez-Sanchez CE, Doi M, Okamura H, Sasano H. 3 $\beta$-hydroxysteroid dehydrogenase isoforms in human aldosterone-producing adenoma. Mol Cell Endocrinol 2015; 408: 205-212.

6 Hattori T, Murase T, Sugiura Y, Nagasawa K, Takahashi K, Ohtake M, Ohtake M, Miyachi M, Murohara T, Nagata K. Effects of salt status and blockade of mineralocorticoid receptors on aldosterone-induced cardiac injury. Hypertens Res 2014; 37: 125-133.

7 Funder JW. The genetics of primary aldosteronism. Science 2011; 331: 685-686.

8 Dunlap JC. Molecuar bases for circadian clocks. Cell 1999; 96: 271-290.

9 Yagita K, Tamanini F, van der Horst G, Okamura H. Molecular mechanisms of the biological clock in cultured fibroblasts. Science 2001; 292: 278-281.

10 Schibler U, Sassone-Corsi P. A web of circadian pacemakers. Cell 2002; 111 : 919-922.
11 Okamura H. Clock genes and cell clocks: roles, actions and mysteries. J Biol Rhythm 2004; 19: 388-399.

12 Pando MP, Morse D, Cermakian N, Sassone-Corsi P. Phenotypic rescue of a peripheral clock genetic defect via SCN hierarchical dominance. Cell 2002; 110: 107-117.

13 Okamura $\mathrm{H}$. Suprachiasmatic nucleus clock time in the mammalian circadian system. Cold Spring Harb Symp Quant Biol 2007; 72: 551-556.

14 Panda S, Antoch MP, Miller BH, Su AI, Schook AB, Straume M, Schultz PG, Kay SA, Takahashi JS, Hogenesch JB. Coordinated transcription of key pathways in the mouse by the circadian clock. Cell 2002; 109: 307-320.

15 Loros JJ, Dunlap JC. Neurospora crassa clock-controlled genes are regulated at the level of transcription. Mol Cell Biol 1991; 11: 558-563.

16 Fustin JM, Doi M, Yamada H, Komatsu R, Shimba S, Okamura H. Rhythmic nucleotide synthesis in the liver: temporal segregation of metabolites. Cell Rep 2012; 1: 341-349.

17 Yin L, Wu N, Curtin JC, Qatanani M, Szwergold NR, Reid RA, Waitt GM, Parks DJ, Pearce KH, Wisely GB, Lazar MA. Rev-erbalpha, a heme sensor that coordinates metabolic and circadian pathways. Science 2007; 318: 1786-1789.

18 Matsuo T, Yamaguchi S, Mitsui S, Emi A, Shimoda F, Okamura H. Control mechanism of the circadian clock for timing of cell division in vivo. Science 2003; 302: 255-259.

19 Jin X, Shearman LP, Weaver DR, Zylka MJ, de Vries GJ, Reppert SM. A molecular mechanism regulating rhythmic output from the suprachiasmatic circadian clock. Cell 1999; 96: 57-68.

20 van der Horst GT, Muijtjens M, Kobayashi K, Takano R, Kanno S, Takao M, de Wit J, Verkerk A, Eker AP, van Leenen D, Buijs R, Bootsma D, Hoeijmakers JH, Yasui A. Mammalian Cry 1 and Cry 2 are essential for maintenance of circadian rhythms. Nature 1999; 398: 627-630.

21 Okamura H, Miyake S, Sumi Y, Yamaguchi S, Yasui A, Muijtjens M, Hoeijmakers JH, van der Horst GT. Photic induction of mPer1 and mPer2 in cry-deficient mice lacking a biological clock. Science 1999; 286: 2531-2534.

22 Yagita K, Tamanini F, van Der Horst GT, Okamura H. Molecular mechanisms of the biological clock in cultured fibroblasts. Science 2001; 292: 278-281.

23 Yamamura K, Doi M, Hayashi H, Ota T, Murai I, Hotta Y, Komatsu R, Okamura H. Immunolocalization of murine type IV $3 \beta$-hydroxysteroid dehydrogenase in the adrenal gland, testis, skin, and placenta. Mol Cell Endocrinol 2014; 382: 131-138.

24 Ota T, Doi M, Yamazaki F, Yarimizu D, Okada K, Murai I, Hayashi H, Kunisue S, Nakagawa $\mathrm{Y}$, Okamura $\mathrm{H}$. Angiotensin II triggers expression of the adrenal gland zona glomerulosa-specific 3 $\beta$-hydroxysteroid dehydrogenase isoenzyme through de novo protein synthesis of the orphan nuclear receptors NGFIB and NURR1. Mol Cell Biol 2014; 34: 3880-3940.

25 Yarimizu D, Doi M, Ota T, Okamura H. Stimulus-selective induction of the orphan nuclear receptor NGFIB underlies different influences of angiotensin II and potassium on the human adrenal zona glomerulosa 33-HSD isoform in H295R cells. Endocr $J$ 2015; 62: 765-776.

26 Sasano H. Localization of steroidogenic enzymes in adrenal cortex and its disorders. Endocr J 1994; 41: 471-482.

27 Sakuma I, Suematsu S, Matsuzawa Y, Saito J, Omura M, Maekawa T, Nakamura Y, Sasano H, Nishikawa T. Characterization of steroidogenic enzyme expression in 
aldosterone-producing adenoma: a comparison with various human adrenal tumors. Endocr J 2013; 60: 329-336.

28 Okamura H, Doi M, Yamaguchi Y, Fustin JM. Hypertension due to loss of clock: nove insight from the molecular analysis of Cry1/Cry2-deleted mice. Curr Hypertens Rep 2011; 13: 103-108.

29 Nugrahaningsih DA, Emoto N, Vignon-Zellweger N, Purnomo E, Yagi K, Nakayama K, Doi M, Okamura H, Hirata K. Chronic hyperaldosteronism in cryptochrome-null mice induces high-salt- and blood pressure-independent kidney damage in mice. Hypertens Res 2014; 37: 202-309.

30 Choi M, Scholl UI, Yue P, Björklund P, Zhao B, Nelson-Williams C, Ji W, Cho Y, Patel A, Men CJ, Lolis E, Wisgerhof MV, Geller DS, Mane S, Hellman P, Westin G, Åkerström G, Wang W, Carling T, Carling T. K+ channel mutations in adrenal aldosterone-producing adenomas and hereditary hypertension. Science 2011; 331: 768-772.

31 Azizan EA, Poulsen H, Tuluc P, Zhou J, Clausen MV, Lieb A, Maniero C, Garg S, Bochukova EG, Zhao W, Shaikh LH, Brighton CA, Teo AE, Davenport AP, Dekkers T, Tops B, Küsters B, Ceral J, Yeo GS, Neogi SG, McFarlane I, Rosenfeld N, Marass F, Hadfield J, Margas W, Chaggar K, Solar M, Deinum J, Dolphin AC, Farooqi IS,
Striessnig J, Nissen P, Brown MJ. Somatic mutations in ATP1A1 and CACNA1D underlie a common subtype of adrenal hypertension. Nat Genet 2013; 45: 1055-1060.

32 Teo AE, Garg S, Shaikh LH, Zhou J, Karet Frankl FE, Gurnell M, Happerfield L, Marker A Bienz M, Azizan EA, Brown MJ. Pregnancy, primary aldosteronism, and adrenal CTNNB1 mutations. N Engl J Med 2015; 373: 1429-1436.

33 Pan A, Schernhammer ES, Sun Q, Hu FB. Rotating night shift work and risk of type 2 diabetes: two prospective cohort studies in women. Plos Med 2011; 8: e1001141.

34 Moser M, Moser M, Schaumberger K, Schernhammer E, Stevens RG. Cancer and rhythm. Cancer Causes Cont 2006; 17: 483-487.

35 Doi M. Circadian clock-deficient mice as a tool for exploring disease etiology. Biol Pharm Bull 2012; 35: 1385-1391.

36 Mohawk JA, Green CB, Takahashi JS. Central and peripheral circadian clocks in mammals. Annu Rev Neurosci 2012; 35: 445-462.

37 Perelis M, Marcheva B, Ramsey KM, Schipma MJ, Hutchison AL, Taguchi A, Peek CB, Hong H, Huang W, Omura C, Allred AL, Bradfield CA, Dinner AR, Barish GD, Bass J. Pancreatic $\beta$ cell enhancers regulate rhythmic transcription of genes controlling insulin secretion. Science 2015; 350: aac4250. 